\title{
Multimodality Imaging in Approach to A Patient with Carcinoid Heart Disease Involving Four Heart Valves
}

Shirin Habibi khorasani ${ }^{1}$, Mozhgan Parsaee ${ }^{1}$, Niloufar Samiei ${ }^{1}$, Mahshid Hesami ${ }^{1}$, Feidoun Noohi $^{1}$, Saeid hosseini ${ }^{1}$, and Golnaz Houshmand ${ }^{1}$

${ }^{1}$ Rajaie Cardiovascular Medical and Research Center

August 21, 2021

\begin{abstract}
Carcinoid heart disease is a rare condition that occurs in half of patients with carcinoid syndrome. The disease mostly affects right-sided heart valves; however, in $5-10 \%$, it can also involve left-sided valves. This case illustrates the most complicated form of the disease with involvement of four heart valves.
\end{abstract}

Hosted file

Carcinoid echo.docx available at https://authorea.com/users/431245/articles/534746multimodality-imaging-in-approach-to-a-patient-with-carcinoid-heart-disease-involvingfour-heart-valves 


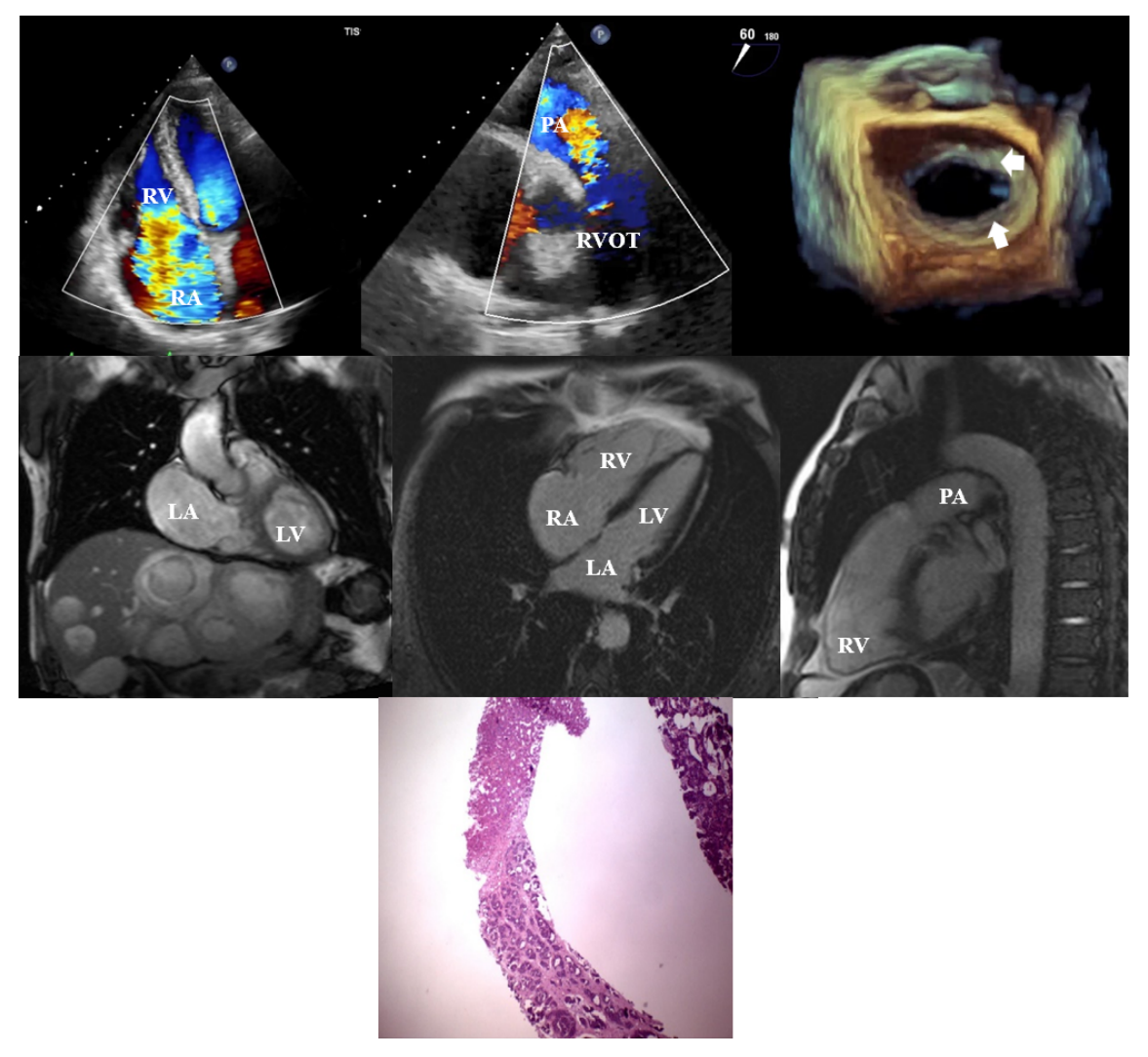

